\title{
EFFECT OF DROUGHT STRESS ON CHLOROPHYLL FLUORESCENCE, AND BIOMASS PORTIONING OF AEGILOPS TAUSCHII L.
}

\author{
ABBAS, A. - YU, H. - CUI, H. - YU, H. - LI, X. ${ }^{*}$ \\ Key Laboratory of Weed and Rodent Biology and Management, Institute of Plant Protection, \\ Chinese Academy of Agricultural Sciences, Beijing, China \\ *Corresponding author \\ e-mail:xjli@ippcaas.cn; phone: +86-10-6281-3309 \\ (Received 19 $9^{\text {th }}$ Sep 2018; accepted 26 $6^{\text {th }}$ Nov 2018)
}

\begin{abstract}
Aegilops tauschii Coss. is one of the problematic weeds, which competes for resources in wheat crop. Drought stress affects productivity, growth, and development of the crops. A greenhouse experiment was conducted to evaluate the effect of different field capacity levels on biomass partitioning and chlorophyll fluorescence on Aegilops tauschii population of China. Dry biomass, plant height, leaf area (LA), leaf area ratio (LAR), specific leaf area (SLA), and the root-shoot ratio (RSR) fluctuated under different field capacity levels and decreased with increasing drought stress level. Maximum dry biomasses, plant height $(1.71 \mathrm{~g}$ and $15.6 \mathrm{~cm})$ were observed in $70-80 \%$ field capacity while the minimum $(0.70 \mathrm{~g}$ and $12.7 \mathrm{~cm})$ were observed under $10-20 \%$ field capacity $(\mathrm{FC})$ level. In root-shoot ratio maximum $(0.72 \mathrm{~g})$ was observed in 50-60\% field capacity level while minimum $(0.60 \mathrm{~g})$ was observed under 10 $20 \%$ field capacity level. Similarly, in LAR and SLA the maximum values $(111.67 \mathrm{~cm}, 175.45 \mathrm{~cm}$ and $433.59 \mathrm{~g})$ were observed in 70-80\% field capacity level while the minimum values $(68.78 \mathrm{~g}, 42.02 \mathrm{~g}$ and $86.32 \mathrm{~g}$ ) were recorded under $10-20 \%$ field capacity level. Similarly, drought stress also influences the $\mathrm{m}$ maximum fluorescence $(\mathrm{Fm})$ in the light-adapted state and has an effect on the maximum quantum yield of PSII. Similarly, the trend was observed in qP (photochemical quenching) and qN (non-photochemical quenching) like minimal and maximal fluorescence.
\end{abstract}

Keywords: growth biomass, abiotic stress, Aegilops tauschii and field capacity, photosynthetic activity, water stress and mechanism of Aegilops tauschii

Abbreviations: LA: Leaf area; LAR: Leaf area ratio; SLA: Specific leaf area; Fo: Minimal fluorescence; F'm: Maximum fluorescence; qP: Photochemical quenching; qN: non-photochemical quenching; PSII: Photosystem II

\section{Introduction}

Goat grass (Aegilops tauschii Coss.) is among one of the noxious exotic weeds (Dudnikov, 2014), with troublesome effect particularly in wheat-growing areas (Zhang et al., 2007). It is native to temperate Asia, tropical Asia and Europe (USDA, 2010). Aegilops tauschii was thought to be an aggressive plant that scattered across more than ten provinces (Fig. 1) of China (Wei et al., 2008, 2007; Su et al., 2013). It competes with the main wheat for capturing resources such as nutrients, light, and water. It reduced the crop's yield because it performs better under environmental stress conditions (Curtis and Halford, 2014). Under natural environmental conditions plant faces different types of environmental constraints such as drought stress, salinity stress and temperature stress (Tatrai et al., 2016; Mittler, 2006; Ibanez et al., 2010). Under different abiotic stresses, plants change their physiological, molecular and cellular conditions (Massa et al., 2013). Water is the main component and has an important role in plant growth and development. Roots have an important role among plant parts to uptake the water under drought condition and distribute in whole plant body (Wang et al., 2013). 


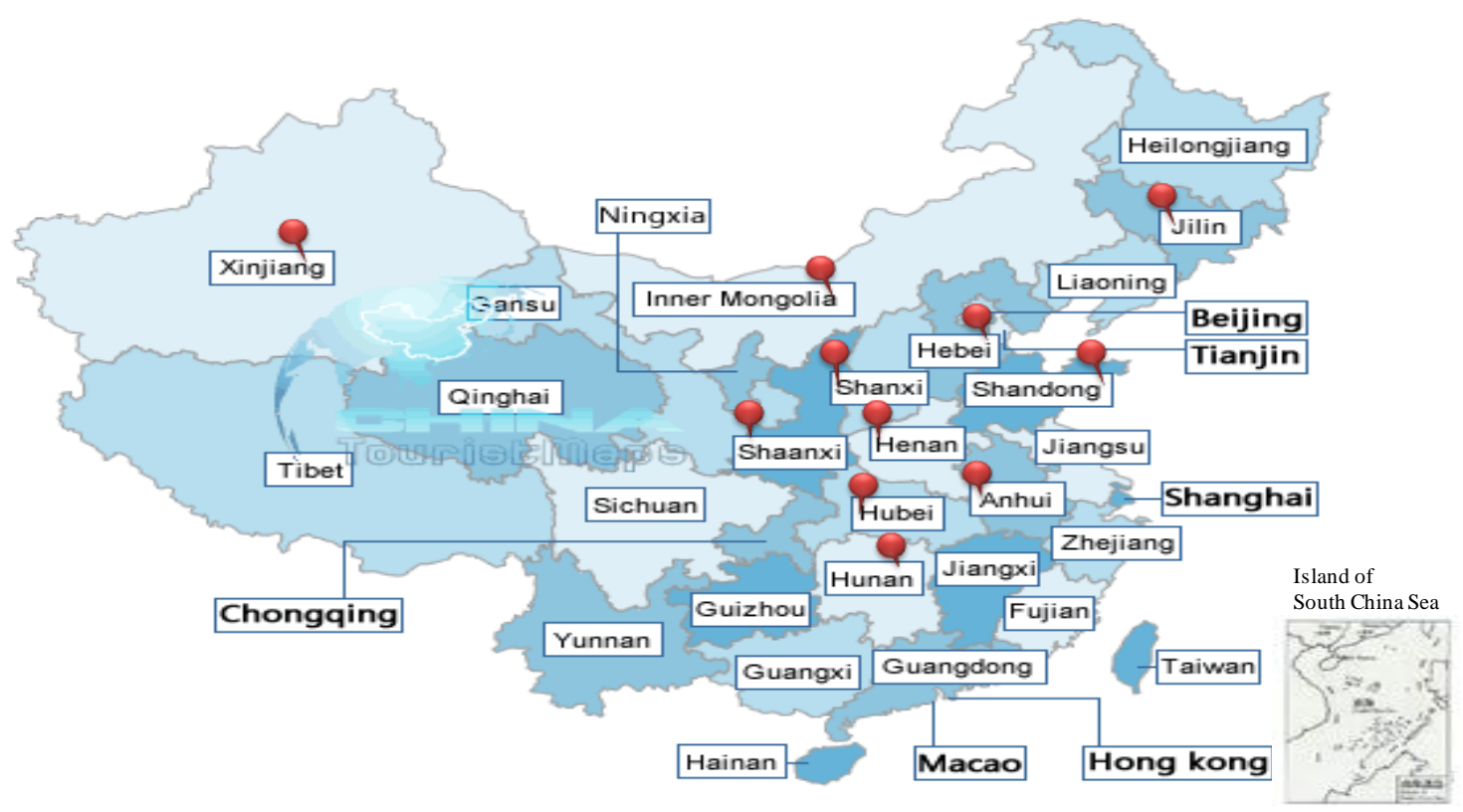

Figure 1. Geographic zones of Aegilops tauschii and red dot indicating the affected provinces

Plant response to limited water is fundamental for implementing crop management strategies (Chaves et al., 2003). Under drought stress levels plants stimulate phonological and biochemical changes which decrease plant growth (Benjamin et al., 2014). Plant growth parameters (plant height, leaf area, dry weight biomass, and chlorophyll fluorescence) are affected under drought condition (Guo et al. (2016). In addition the photosynthetic activity is directly affected under water stress condition (Wu et al., 2010). The crop vulnerability under drought stress depends upon the duration of growth stages, plant species, and stress intensity (Singh et al., 2013). One of the prominent techniques for attaining comprehensive estimates of photosynthetic activities is chlorophyll fluorescence. Chlorophyll fluorescence is an important and fast technique for the examination of photosyntheic activities (Sajbidorova et al., 2015). Plant biochemistry and function of PSII are affected by different abiotic stresses (Yang, 2013). Drought stress significantly effects maximal fluorescence (Fm), maximum fluorescence in the light-adapted state $\left(\mathrm{F}^{\prime} \mathrm{m}\right)$, the maximum quantum yield of PSII, photochemical quenching $\mathrm{qP}$ and non-photochemical quenching $\mathrm{qN}$ (Dias and Bruggemann, 2010). Similarly, Cendrero-Mateo et al., 2015 along with Van der Tol et al., 2009 reported that accessibility of light, nutrition, and drought stress manipulate the relationship between photosynthesis, chlorophyll fluorescence, and non-photochemical quenching.

In general, under different abiotic stress conditions chlorophyll fluorescence is a dominant technique for photosynthetic activity (Barbagallo et al., 2003; Proctor et al., 2003; Gottardini et al., 2014). This technique has been used in the study of wheat stress response under different abiotic stress conditions, such as water stress (Eduardo et al., 2002), heat stress (Lu et al., 1999, 2001; Chaerle et al., 2007), cold stress (Rizza et al., 2001; Ying et al., 2002), salt stress (Lu et al., 2003), and nitrogen deficiency (Lu et al., 2001; Shangguan et al., 2000) (Sampol et al., 2003). As we know Aegilops tauschii is a rich source of genetic material and perform better under biotic and abiotic stress condition (Assefa and Fehrmann, 2000; Hsam et al., 2001; Colmer et al., 2006). 
Some studies investigated the biological characteristic in different crop plant species under different abiotic stresses (Ma et al., 2010). In order to ascertain control strategies for resistant weeds, problem-solving approaches of the species characters should be constructed (Beffa, 2012). Chlorophyll fluorescence was observed on barley leaves when the carbon assimilation was affected (Quick and Horton, 1984). It started an era for stress detection on photosynthesis with chlorophyll fluorescence measurement. In weed science, herbicide stress on Photosystem II (PSII) was used for the dose optimization by measuring photosynthetic efficiency (Kempenaar et al., 2010). Chlorophyll fluorescence was used to quantify the agar-based Syngenta 'RISQ' test and detected the herbicide resistance in Alopecurus myosuroides depending on the dose response analysis (Kaundun et al., 2011; Wang et al., 2015). Due to the fast-growing habit under the stressful environmental condition, we design an experiment to evaluate the effect of different field capacity levels on biomass partitioning and chlorophyll fluorescence of Aegilops tauschii. The objective of this study is to develop a method capable to be used in the field for measuring chlorophyll fluorescence quantum yield of PSII (Fv/Fm) under different water capacity level. The results would contribute to the strategic decision to understand the behavior of Aegilops tauschii under different field capacity level.

\section{Materials and method}

\section{Plant materials, growth conditions, and stress treatments}

A greenhouse experiment was conducted at The Institute of Plant Protection, Chinese Academy of Agricultural Sciences, Beijing, China. Aegilops tauschii seeds were collected from five different parts of China. After drying for one week in open sunlight, deformed and damaged seeds were discarded, and apparently healthy seeds were airdried and then stored at $4{ }^{\circ} \mathrm{C}$. Before sowing seeds were soaked in water for $24 \mathrm{~h}$. A complete randomized design was applied under four replication with four treatments of different field capacity levels (10-20\% (D1), 30-40\% (D2), 50-60\% (D3) and 70-80\% (D4). Seeds of similar size were sown in plastic pots $(15 \mathrm{~cm}$ in diameter and $13 \mathrm{~cm}$ in height) with seven seeds per pot in June 2017. Each pot contained similar volumes of sandy loam soil, and hummus in a ratio of 3:1. Initially, pots were watered thoroughly, with soil moisture maintained at about $80-100 \%$ field capacity, to ensure the seed germination. Fifteen days after sowing different field capacity levels were maintained in the pots according to the experimental layout and continued until 60 DAS treatment instigation. Soil moisture was measured by using a TDR soil moisture meter (TRIMEPICO, Germany).

\section{Growth parameters}

Plant height was measured with a meter rod from the base of the plant to the leaf tip. The height of five chosen plants was measured in each pot and was averaged. Leaf area was measured by a portable leaf meter, and five plants from each pot were selected for further analysis. For recording dry biomass allocation data five plants were removed carefully and washed for the further procedure; the plants were separated into root and shoot put into an oven and dried for $48 \mathrm{~h}$, dry weight was measured with a digital weight balance. Leaf area ratio was determined as follows: total leaf area divided by dry weight biomass. Specific leaf area (SLA) is measured as the ratio of leaf area to dry mass. 


\section{Chlorophyll fluorescence}

Chlorophyll fluorescence was measured with an imaging-PAM Mini-Series (IMAGK5, Walz Germany) (Fig. 2) following the procedure described by van Kooten and Snel (1990). Chlorophyll fluorescence imaging-PAMs are highly sensitive research instruments which give quantitative information on the quantum yield of photosynthetic energy conversion. Selected plants of Aegilops tauschii were placed in the darkroom for $30 \mathrm{~min}$ before measuring the Chlorophyll fluorescence under the different field capacity levels. This imaging-PAM mini-series was used to measure minimum fluorescence $\left(\mathrm{Fo}^{\prime}\right)$, maximum fluorescence $\left(\mathrm{F}^{\prime} \mathrm{m}\right)$, the quantum yield of PSII (ФPSII), photochemical quenching (qP) and non-photochemical quenching (qN). The photochemical quenching $(\mathrm{qP})(E q .1)$ and non-photochemical quenching $(\mathrm{qN})(E q .2)$ was determined by the following formula shown in Equations 1 and 2.

$$
\begin{aligned}
& \mathrm{qP}=\left(F^{\prime} \mathrm{m}-\mathrm{Fs}\right) /\left(F^{\prime} \mathrm{m}-\mathrm{F} 0\right) \\
& \mathrm{qN}=\left(\mathrm{Fm}-\mathrm{F}^{\prime} \mathrm{m}\right) / \mathrm{F}^{\prime} \mathrm{m}
\end{aligned}
$$

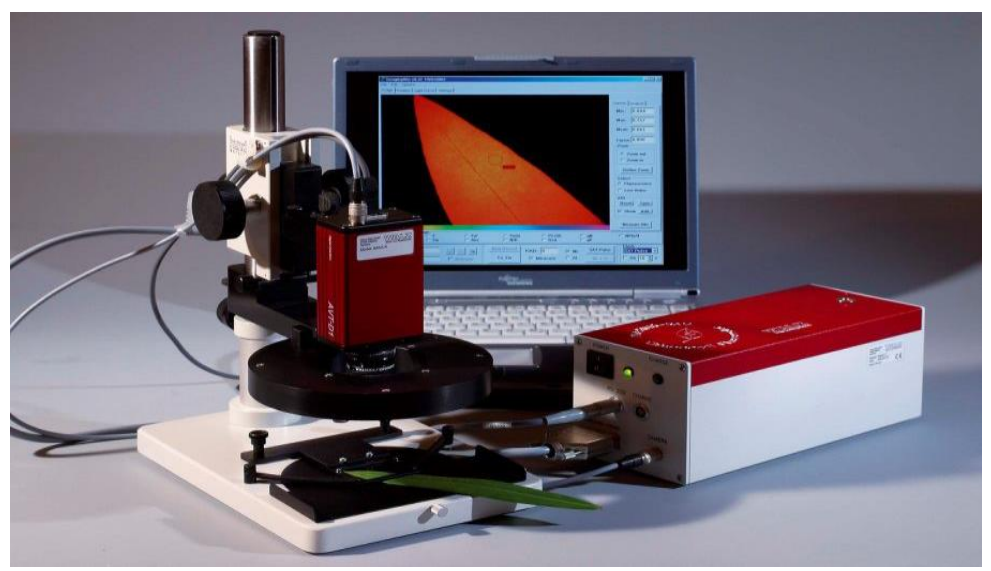

Figure 2. PAM M-series used for chlorophyll fluorescence parameters

\section{Statistical analysis}

Statistix 8.1 software (Analytical software, Statistix; Tallahassee, FL, USA, 19852003) was used for statistical data extrapolation. Analysis of variance (ANOVA) for plant dry weight biomass, root biomass, and leaf weight biomass was used to find out the effect of treatments and Tukey's honest significance difference (HSD) test was used at 0.05 probabilities to compare the differences among the treatment means. All the results are expressed in standard error (SE) and shown in the figures.

\section{Results}

\section{Effect of different field capacity level on growth parameters}

Drought stress significantly affects all the parameter under study about biomass partitioning and chlorophyll fluorescence. Chlorophyll fluorescence and growth parameter significantly decreased with increasing drought stress level. Data regarding dry weight biomass of Aegilops tauschii under different field capacity level (Table 1) 
indicated that dry weight biomass was significantly $(\mathrm{p}<0.05)$ influenced by different field capacity level, maximum dry weight biomass $(1.71 \mathrm{~g})$ was recorded under $80 \%$ field capacity level, and the minimum $(0.70 \mathrm{~g})$ was recorded in lower field capacity level (10-20\%). The maximum reduction (59\%) in dry weight biomass was recorded in (10-20\%) field capacity level respectively. In this study, maximum plant height $(15.6 \mathrm{~cm})$ was recorded under $70-80 \%$ field capacity level while minimum $(12.7 \mathrm{~cm})$ was recorded in lower field capacity level. The maximum reduction in plant height (18.5\%) was under 10-20\% field capacity level. Regarding root-shoot data, the maximum value $(0.72 \mathrm{~g})$ was recorded in $70-80 \%$ field capacity level while the minimum (0.60) was recorded under 10-20\% field capacity level. The reduction with decreasing water field capacity was (16.6\%) under $10-20 \%$ field capacity level. Regarding leaf area data the maximum (Fig. 3) $(111.67 \mathrm{~cm})$ was recorded under $80 \%$ field capacity level while the minimum $(68.78 \mathrm{~cm})$ was recorded under lower field capacity $(10-20 \%)$ level. The maximum reduction in leaf area $(38 \%)$ was recorded through lower field capacity level. Leaf area ratio (LAR) and specific leaf area (SLA) were significantly affected under field capacity levels, the maximum LAR and SLA (175.45 and 433.59) was recorded under $80 \%$ field capacity level while the minimum (42.02 and 86.32) was recorded under lower field capacity level (10-20\%). The maximum reduction (76\% and $80 \%)$ in LAR and SLA was recorded through a decreasing field capacity level.

Table 1. Dry weight biomass, plant height, leaf area $(\mathrm{cm})$, leaf area ratio, specific leaf area and root shoot ratio of Aegilops tauschii under different field capacity levels

\begin{tabular}{c|c|c|c|c|c|c}
\hline Field capacity & Dry weight & Plant height $(\mathbf{c m})$ & Leaf area & LAR & SLA & R/S ratio \\
\hline DI & $0.70 \mathrm{C}$ & $12.7 \mathrm{C}$ & $68.78 \mathrm{~B}$ & $42.02 \mathrm{~B}$ & $86.32 \mathrm{~B}$ & $0.60 \mathrm{~A}$ \\
$\mathrm{D} 2$ & $0.98 \mathrm{C}$ & $13.5 \mathrm{BC}$ & $92.22 \mathrm{AB}$ & $77.76 \mathrm{~B}$ & $147.63 \mathrm{~B}$ & $0.71 \mathrm{~A}$ \\
$\mathrm{D} 3$ & $1.19 \mathrm{~B}$ & $15 \mathrm{AB}$ & $99.95 \mathrm{~A}$ & $102.10 \mathrm{~B}$ & $239.5 \mathrm{AB}$ & $0.72 \mathrm{~A}$ \\
D4 & $1.71 \mathrm{~A}$ & $15.6 \mathrm{~A}$ & $111.67 \mathrm{~A}$ & $175.45 \mathrm{~A}$ & $433.59 \mathrm{~A}$ & $0.68 \mathrm{~A}$ \\
\hline
\end{tabular}

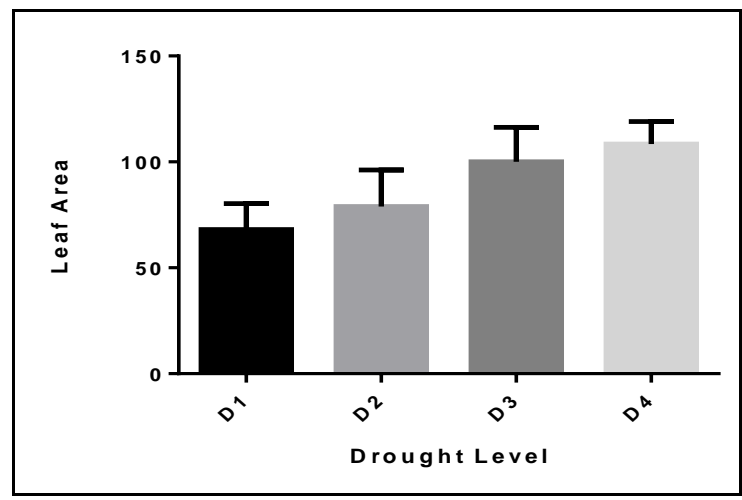

Figure 3. Effect of different capacity levels on leaf area $\left(\mathrm{m}^{2}\right)$ of Aegilops tauschii L.

\section{Effect of different field capacity levels on chlorophyll fluorescence}

Photosynthetic activity (Chlorophyll Fluorescence) was significantly affected under different capacity levels. In different field capacity levels the maximum minimal fluorescence (Fo') was recorded under $20 \%$ field capacity and gradually decreased with 
increasing field water capacity, and reached a 0.12 value at maximum field capacity (7080\%). Maximal fluorescence (Fm) (Fig. 4b) was recorded (0.32) in 70-80\% field capacity and minimum fluorescence (Fig. 4a) (0.20) was recorded under $10-20 \%$ field capacity. Under different field capacity levels values of the quantum yield of PSII (Fv/Fm) reaction centre were recorded. Maximum PSII (Fig. 5a) (0.44) was recorded under 70-80\% field capacity level while minimum (0.29) was recorded under $10-20 \%$ field capacity level. Similarly, trend was observed in effective quantum yield on Photosystem II (Fig. 5b). The photochemical quenching ingenuousness of the center of PSII determines the proportion of energy engrossed by photosystem pigments, which is used for photosynthesis (Van Kooten and Snel, 1990). In addition, the results showed that photochemical quenching qP (Fig. 6a) was increased under 70-80\% field capacity and reached a maximum (0.52) and decreased gradually with decreasing field water capacity and reached a minimum (0.39) level. The non-photochemical quenching (qN) (Fig. 6b) is an important mechanism to protect the plant. In non-photochemical quenching $\mathrm{qN}=\left(\mathrm{Fm}-\mathrm{F}^{\prime} \mathrm{m}\right) / \mathrm{F}^{\prime} \mathrm{m}$ directly corelate with field capacity level. An increase in non-photochemical quenching was observed with an increase of field capacity level. Maximum non-photochemical quenching (0.79) was recorded under 70-80\% field capacity level and reached a minimum (0.61) at $20 \%$ capacity level.
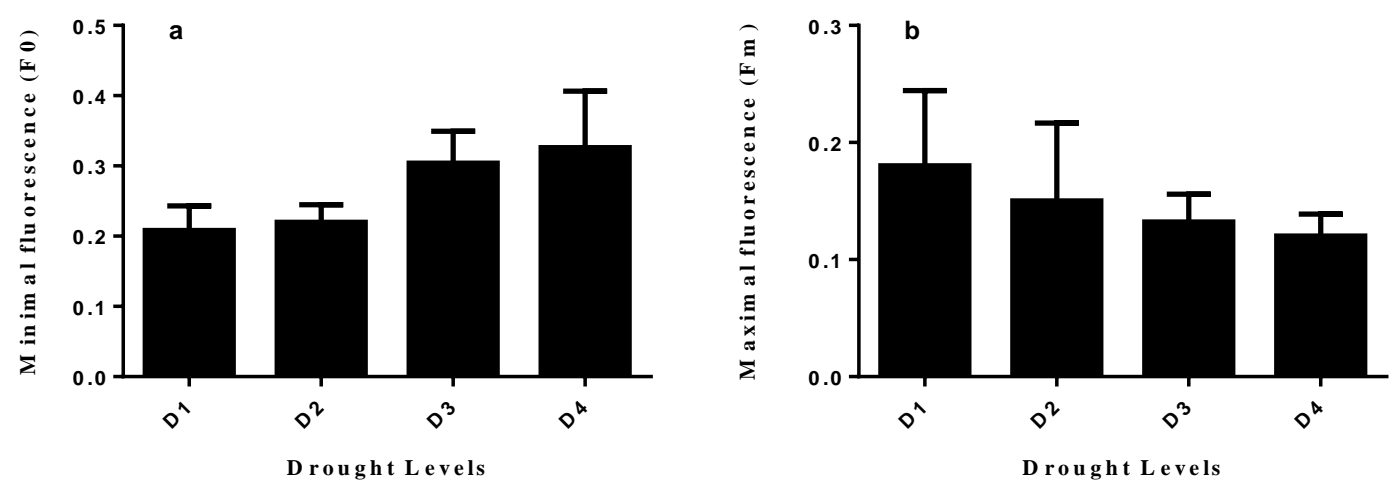

Figure 4. Effect of different capacity levels on minimal fluorescence and maximal fluorescence of Aegilops tauschii L. Bars are expressed as $\pm S E$
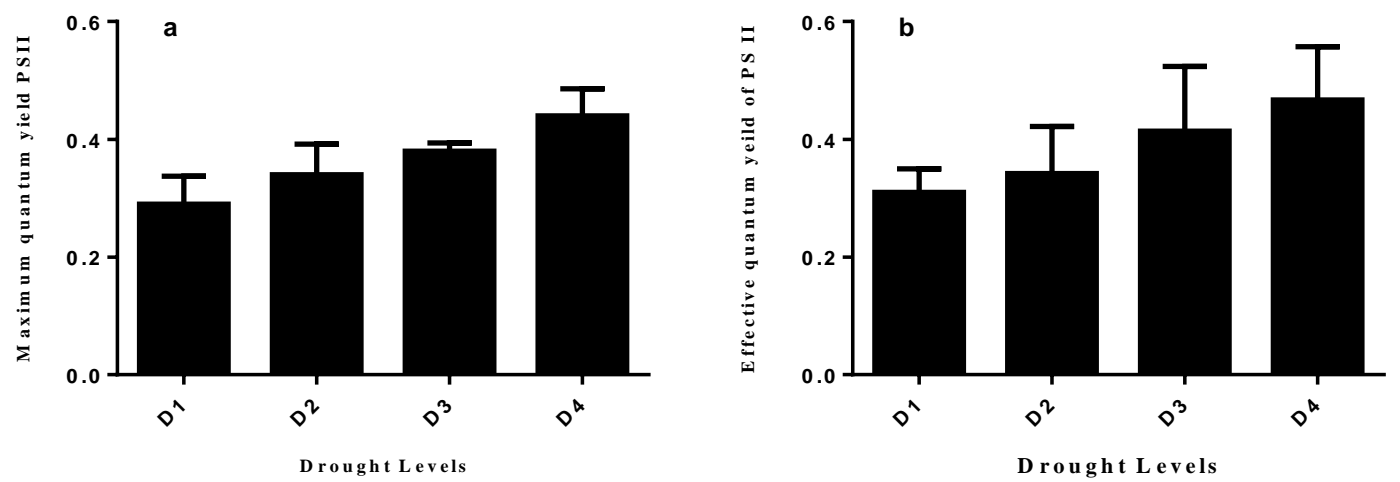

Figure 5. Effect of different capacity levels on the maximum quantum yield on Photosystem II and effective quantum yield on Photosystem II under different field capacity levels 

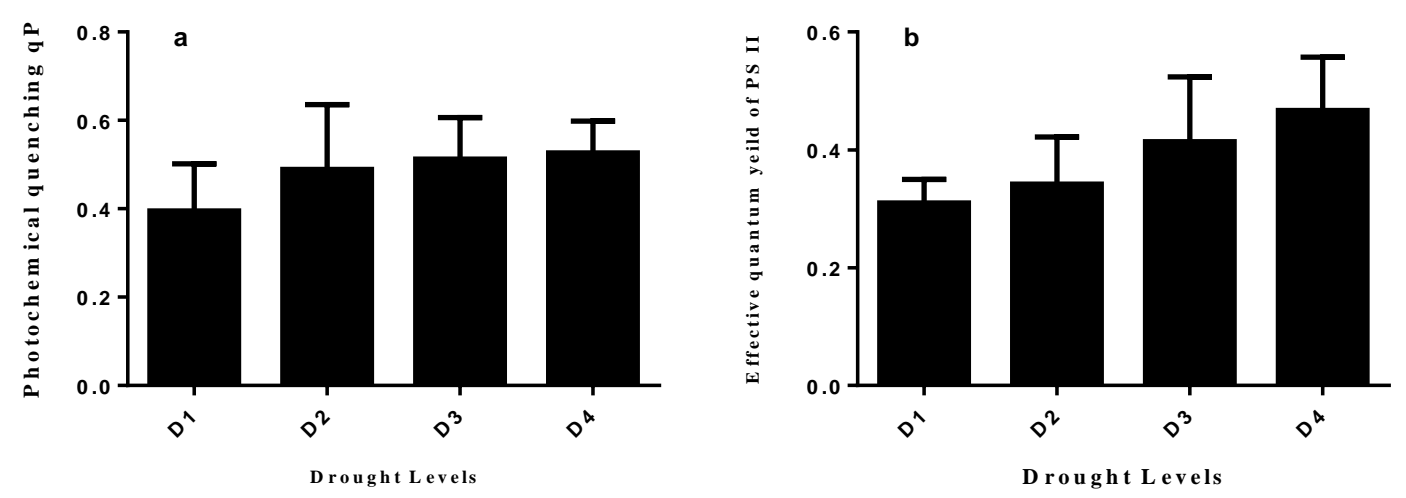

Figure 6. Effect of different capacity levels on photochemical quenching $(q P)$ and nonphotochemical quenching (qN) of Aegilops tauschii L. Bar are expressed as $\pm S E$

Under drought stress duration non-photochemical quenching (qN) showed a decline, at $70-80 \%$ field capacity a qN value of 0.79 was recorded, which was higher than at $10-$ $20 \%$ field capacity (0.61). This showed that the degree of ingenuousness of PS II and reaction center under drought stress condition were very low as compared to high field capacity (70-80\%), which affect the photosynthetic activity in plants. In our study plant leaves and photosynthetic activity severely damaged under lower field capacity which led to decrease in Fm', Fv/Fm, ФPSII, QP, and qN. While Aegilops tauschii performed better under drought stress condition.

\section{Discussion}

In the present study, we analyzed the effect of different field capacity levels on the biomass portioning and chlorophyll fluorescence on Aegilops tauschii. The plants were irrigated after three days interval. The Aegilops tauschii was surviving better under high water stress at 20\% field capacity. Under lower field capacity Aegilops tauschii shows aggressiveness and perform better. According to the above results, under higher field capacity Aegilops tauschii growth is higher than in lower field capacity. This competitive utilization of water in Aegilops tauschii in an early stage help to utilize more water content of the soil and initiates more rapid growth as compared to the wheat crop. Aegilops tauschii can uptake more water as compared to another crop.

However, lower field capacity level (10-20\%) negatively affected the leaves, root, and plant dry biomass of Aegilops tauschii. Water is an important component for growth, development, and production (Kabbas et al., 2018). Likewise, Bortolheiro and Silva (2017) and Yamaguchi-Shinozaki and Shinozaki (2006) reported that accessibility and unavailability of proper water seriously affect the biochemical processes, physiology, and morphology of crop plants. Plant growth and biomass allocation are affected under drought stress (Li et al., 2008) and with the variation in availability of water vary the growth and biomass of the plants (Padilla et al., 2009). Chuhan (2013) reported a decrease in biomass production of switch grass under lower field capacity level.

Plants under different drought stress conditions decreased the dry biomass and distorted the biomass allocation from root to leaves. We also conclude that under lower 
field capacity dry biomass significantly increases and Aegilops tauschii survive better. Similarly, results were found in Prunus mongolica in root to shoot ratio under different field capacity levels (Guo et al., 2015; Liu et al., 2017). Similarly, in our study different field capacity levels affected Aegilops tauschii growth. Rehimi et al. (2010) said that Plantago ovata and P. psyllium are significantly affected under drought stress condition. Azevedo (2011) reported under lower field capacity Carapa guianensis has maximum growth and biomass. In our study, Aegilops tauschii was suppressed under lower field capacity (20 to $40 \%$ ) level. This may be due to a survival mechanism and growth under different conditions. Under lower water field capacity plant height decreased due to a decline in cell enlargement (Li et al., 2008; Manivannan et al., 2007; Wang et al., 2013). Likewise, Moran and Shower (2005) said that lower field capacity affects or decrease the fresh weight and shoot weight (35\% and 35\%) of A. palmeri S. Continuous water stress affect the smaller leaf of dwarf plants (Haffani et al., 2014).

Under different abiotic stress conditions, chlorophyll fluorescence is an important and common method to determine the leaves photosynthetic activity (Resco et al., 2008). Moreover, Lichteuthaler and Miehe (1997) said that plant leaves are sensitive in nature under drought stress condition, decreased the photosynthetic rate at Photosystem II and increased the non-photochemical quenching. In our experiment, lower field capacity greatly affected the chlorophyll fluorescence of Aegilops tauschii and considerably decline with a decreasing of field capacity level. The date related to chlorophyll fluorescence of Aegilops tauschii. Minimal fluorescence (Fo) increased, while maximal fluorescence (Fm) decreased with increasing field capacity level. This showed that the transportation energy absorbed by Photosystem II partially suppressed the photochemical reaction.

The increase in energy by fluorescence and thermal debauchery loss evidently reduced the photosynthesis energy. Under lower field capacity, photosynthetic activity of Aegilops tauschii was damaged that gradually decreased the Fv/Fm value. This showed that the initial reaction of photosynthesis in Aegilops tauschii is concealed and the exchange competence of light energy was decreased by inhibiting the potential active center. Chlorophyll fluorescence (Fo) is a powerful component under drought stress condition (Percival and Sheriffs, 2002). The photochemical quenching imitates to an increase in minimal fluorescence and a decrease in maximum fluorescence (Fm) or a ratio of Fv/Fm (Thomas and Turner, 2001). In Aegilops tauschii, photochemical quenching and non-photochemical quenching was deceased under lower field capacity level. An important component of Photosystem II is photochemical quenching (qP) ( $\mathrm{Li}$ et al., 2013), and protection system under stress condition is non-photochemical quenching (qN). It showed the proportion of energy absorbed by the PSII pigment but debauched as a heat (Maxwell and Johnson, 2000). Aegilops tauschii photosystem II was significantly damaged due to decreased non-photochemical quenching (qN) and trouncing of heat indulgence potential. This showed that long-term lower water availability affects the photosynthetic process in Aegilops tauschii which partially suppressed the photochemical reactions. Similarly, this kind of results have been reported in different crops, such as sugar beet (Sikuku et al., 2010) Coronnilla varia (Yang et al., 2013) In P. mongolica and L. ruthenicum (Guo et al., 2015) it was showed that chlorophyll fluorescence parameters are extensively affected under different field capacity levels. 


\section{Conclusion}

This study revealed the survival mechanism of Aegilops tauschii under different field capacity levels. In conclusion, our results showed that lower field capacity affects the biomass portioning and chlorophyll fluorescence of Aegilops tauschii. Furthermore, all growth-related parameters start declining under 20 to $40 \%$ field capacity, the growth and survival of Aegilops tauschii were adversely affected under higher field capacity of 60 to $80 \%$. Likewise, lower field capacity level damages Aegilops tauschii leaves, photosynthetic activity that leads to a decrease in minimal fluorescence (F0), maximal fluorescence $(\mathrm{Fm})$, and maximum quantum yield of PSII $(\mathrm{Fv} / \mathrm{Fm})$, photochemical quenching $\mathrm{qP}$ and non-photochemical quenching $\mathrm{qN}$, therefore, lower field capacity level severely affects Aegilops tauschii.

Acknowledgements. This study was funded by the "National key Research and Development Program of China (2106YFD0300701) and the earmarked fund for China Agriculture Research System (CARS-25).

Conflict of interests. The authors declare that they have no conflict of interests.

\section{REFERENCES}

[1] Assefa, A., Fehrmann, H. (2000): Resistance to wheat leaf rust in Aegilops tauschii Coss. and inheritance of resistance in hexaploid wheat. - Genetic Resources and Crop Evolution 47: 135-140.

[2] Azevedo, G. F. D. C. (2011): Photosynthetic parameters and growth in seedlings of Bertholletia excelsa and Carapa guianensis in response to pre-acclimations to full sunlight and mild water stress. - Acta Amazonica 44: 67-77.

[3] Barbagallo, R. P., Oxborough, K., Pallett, K. E., Baker, N. R. (2003): Rapid, noninvasive screening for perturbations of metabolism and plant growth using chlorophyll fluorescence imaging. - Plant Physiology 132: 485-493.

[4] Beffa, R., Figge, A., Lorentz, L., Hess, M., Laber, B., Ruiz-Santaella, J. P. (2012): Weed resistance diagnostic technologies to detect herbicide resistance in cereal-growing areas. A review. - Julius-Kuhn-Archiv 434: 75-78.

[5] Benjamin, J. G., Nielsen, D. C., Vigil, H. F., Mikha, M. M., Calderon. F. (2014): Water deficit stress effects on corn (Zea mays L.). - Open Journal of Soil Science 4: 151-160.

[6] Bortolheiro, F. P. A. P., Silva, M. A. (2017): Physiological response and productivity of safflower lines under water deficit and rehydration. - Anais da Academia Brasileira de Ciências 89: 3051-3066.

[7] Cendrero-Mateo, M. P., Carmo-Silva, A. E., Porcar-Castell, A., Hamerlynck, E. P., Papuga, S. A., Moran, M. S. (2015): Dynamic response of plant chlorophyll fluorescence to light, water, and nutrient availability. - Function of Plant Biology 42: 8-12.

[8] Chaerle, L., Leinonen, I., Jones, H. G., Straeten, D. V. D. (2007): Monitoring and screening plant populations with combined thermal and chlorophyll fluorescence imaging. - Journal of Experimental Botany 58: 773-784.

[9] Chauhan, B. S. (2013): Growth response of switchgrass (Rottboellia cochinchinensis) to water stress - Weed Science. 61: 98-103.

[10] Chaves, M. M., Maroco, J. P., Pereira, J. S. (2003): Understanding plant responses to drought from genes to the whole plant. - Functional of Plant Biology 12: 239-264.

[11] Colmer, T. D., Flowers, T. J., Munns, R. (2006): Use of wild relatives to improve salt tolerance in wheat. - Journal of Experimental Botany 57: 1059-1078. 
[12] Curtis, T., Halford, N. G. (2014): Food security: the challenge of increasing wheat yield and the importance of not compromising food safety. - Annals of Applied Biology 164: 354-372.

[13] Dias, M. C., Bruggemann, W. (2010): Limitations of photosynthesis in Phaseolus vulgaris under drought stress: gas exchange, chlorophyll fluorescence, and Calvin cycle enzymes. - Photosystem 48: 96-102.

[14] Dias, M. C., Bruggemann, W. (2010): Limitations of photosynthesis in Phaseolus vulgaris under drought stress: gas exchange, chlorophyll fluorescence, and Calvin cycle enzymes. - Photosystem 48: 96-102.

[15] Eduardo Adonias DeSousa, M. D., Ross, H. Albert, B. A., Bernadette Kalman, M. D. (2002): Cognitive impairments in multiple sclerosis: A review. - American Journal of Alzheimer's Disease \& Other Dementias 17: 23-29.

[16] Gottardini, E., Cristofori, A., Cristofolini, F., Nali, C., Pellegrini, E., Bussotti, F., Ferretti, M. (2014): Chlorophyll-related indicators are linked to visible ozone symptoms: evidence from a field study on native Viburnum lantana L. plants in northern Italy. - Ecological Indicators 39: 65-74.

[17] Guo, Y., Hongyuan, Y., Dongsheng, K, Fang, Y., Donghua, L., Yajuan, Z. (2015). Effects of gradual soil drought stress on the growth, biomass partitioning, and chlorophyll fluorescence of Prunus mongolica seedlings. - Turkish Journal of Biology 39: 532-539.

[18] Guo, Y. Y., Yu, H. Y., Kong, D. S., Yan, F., Zhang, Y. J. (2016): Effects of drought stress on growth and chlorophyll fluorescence of Lycium ruthenicum Murr. seedlings. Photosynthetica 54(4): 524-531.

[19] Haffani, S., Mezni, M., Slama, I., Ksontini, M., Chalabi, W. (2014): Plant growth, water relations and proline content of three vetch species under water-limited conditions. Grass and Forage Science 69: 323-333.

[20] Hsam, S. L. K., Kieffer, R., Zeller, F. J. (2001): The significance of Aegilops tauschii glutenin genes on bread-making properties of wheat. - Cereal Chemistry 78: 521-525.

[21] Ibanez, H., Ballester, A., Munoz, R., Jose, Q. M. (2010). Chlororespiration and tolerance to drought, heat and high illumination. - Journal of Plant Physiology. 167: 732-738.

[22] Kaundun, S. S., Hutchings, S. J., Dale, R. P., Bailly, G. C., Glanfield, P. (2011): Syngenta RISQ test: a novel in-season method for detecting resistance to post-emergence ACCase and ALS inhibitor herbicides in grass weeds. - Weed Research 51: 284-293.

[23] Kebabs, S., Benseddik, T., MakhloufI, H., Aid, F. (2018). The physiological and biochemical behavior of Gleditsia triacanthos L. Young seedlings under drought stress conditions. - Notulae Botanicae Horti Agrobotanici 46: 585-592.

[24] Kempenaar, C., Lotz, L. A. P., Snel, J. F. H., Smutny, V., Zhang, H. J. (2011): Predicting herbicidal plant mortality with mobile photosynthesis meters. - Weed Research 51: 1222.

[25] Korten, O. V., Snel, J. (1990): The use of chlorophyll fluorescence nomenclature in plant stress physiology. - Photosynthesis Research 25: 147-50.

[26] Krause, G. H., Weis, E. (1991): Chlorophyll fluorescence and photosynthesis: the basics. - Annual Review of Plant Physiology and Plant Molecular Biology 42: 313-349.

[27] Li, F. L., Bao, W. K., Wu, N., You, C. (2008): Growth biomass partitioning, and wateruse efficiency of a leguminous shrub (Bauhinia faberi var. microphylla) in response to various water availabilities. - New Forest 36: 53-65.

[28] Li, G. L., Wu, H. X., Sun, Y. Q. (2013): The response of chlorophyll fluorescence parameters to drought stress in sugar beet seedlings. - Russian Journal of Plant Physiol. 60: 337-342.

[29] Lichteuthaler, H. K., Miehe, J. A. (1997): Fluorescence imaging as a diagnostic tool for plant stress. - Trends in Plant Sciences 2: 316-320.

[30] Liu, Y., Li, P., Xu, G. C., Xiao, L., Ren, Z. P., Li, Z. B. (2017): Growth, morphological and physiological responses to drought stress in Bothriochloa ischaemum. - Frontier in Plant Science 8: 230-237. 
[31] Lu, C. M., Vonshak, A. (1999): Characterization of PSII photochemistry in salt-adapted cells of the cyanobacterium Spirulina platensis. - New Phytologist 141: 231-239.

[32] Lu, C. M., Zhang, J. H. (1998): Effects of water stress on photosynthesis, chlorophyll fluorescence and photoinhibition in wheat plants. - Australian Journal of Plant Physiology 25: 883-892.

[33] Lu, C. M., Zhang, J. H., Zhang, Q. D., Li, L. B., Kuang, T. Y. (2001): Modification of photosystem II photochemistry in nitrogen deficient maize and wheat plants. - Journal of Plant Physiology 158: 1423-1430.

[34] Lu, C. M., Qiu, N., Wang, B., Zhang, J. H. (2003): Salinity treatment shows no effects on Photosystem II photochemistry but increases the resistance of Photosystem II to heat stress in halophyte Suaeda salsa. - Journal of Plant Physiology 54: 851-860.

[35] Ma, J., Ni, X., Shi, H. Y., Liu, W. Z. (2010): Flowering biology of Amygdalus mongolica. - Acta Botanica Boreali-Occidentalia Sinica 30: 1134-1141.

[36] Manivannan, P., Jaleel, C. A., Kishorekumar, A., Sankar, B., Somasundaram, R., Sridharan, R., Panneerselvam, R. (2007): Changes in the antioxidant metabolism of Vigna unguiculata L. by propiconazole under water deficit stress. - Colloids and Surfaces B: Biointerfaces 57: 69-74.

[37] Massa, A. N., Kevin, L., Buell, R. C. (2013): Abiotic and biotic stress responses in Solanum tuberosum group Phureja DM1-3 516 R44 as measured through whole transcriptome Sequencing. - The Plant Genome 6: 1-10.

[38] Maxwell, K., Johnson, G. N. (2000): Chlorophyll fluorescence: a practical guide. Journal of Experimental Botany 51: 659-668.

[39] Mittler, R. (2006): Abiotic stress the field environment and stress combination. - Trends in Plant Science 11: 15-19.

[40] Moran, P. J., Showler, A. T. (2005): Plant responses to water deficit and shade stresses in pigweed and their influence on feeding and oviposition by the beet armyworm (Lepidoptera: Noctuidae). - Environmental Entomology 34: 929-937.

[41] Percival, G. C., Sheriffs, C. N. (2002): Identification of drought-tolerant woody perennials using chlorophyll fluorescence. - Journal of Arboriculture 28: 215-223.

[42] Padilla, F. M., Ortegab, R., Sanchezab, J., Pugnairea, F. I. (2009): Rethinking species selection for restoration of arid shrublands. - Cellular and Molecular Life Sciences 66(1): 173-86.

[43] Proctor, M. C. F. (2003): Comparative ecophysiological measurements on the light responses, water relations and desiccation tolerance of the filmy ferns Hymenophyllum wilsonii Hook and H. tunbrigense (L.). - Annals of Botany 9: 717-727.

[44] Quick, W. P., Horton, P. (1984): Studies on the induction of chlorophyll fluorescence in barley protoplasts. Factors affecting the observation of oscillations in the yield of chlorophyll fluorescence and rate of oxygen evolution. - Proceedings of the Royal Society of London Series B Biological Sciences 220: 361-370.

[45] Rahimi, A., Husseini, S. M., Pooryoosef, M., Fateh, I. (2010): Variation of leaf water potential, relative water content, and SPAD under gradual drought stress and stress recovery in two medicinal species of Plantago ovata and P. psyllium. - Plant Ecophysiology 2: 53-60.

[46] Resco, V., Ignace, D. D., Sun, W., Huxman, T. E., Weltzin, J. F., Williams, D. G. (2008): Chlorophyll fluorescence, predawn water potential, and photosynthesis in precipitation pulse-driven ecosystems-implications for ecological studies. - Functional Ecology 22: 479-83.

[47] Rizza, F., Pagani, D., Stanca, A. M., Cattivelli, L. (2001): Use of chlorophyll fluorescence to evaluate the cold acclimation and freezing tolerance of winter and spring oats. - Plant Breeding 120: 389-392.

[48] Sajbidorova, V., Lichtnerova, H., Paganova, V. (2015): The impact of different water regime on chlorophyll fluorescence of Pyrus pyraster L. Sorbus domestica L. - Acta Universitatis Agriculturae et Silviculturae Mendelianae Brunensis 63: 1575-1579. 
[49] Sampol, B., Bota, J., Riera, D., Medrano, H., Flexas, J. (2003): Analysis of the virusinduced inhibition of photosynthesis in malmsey grapevines. - New Phytology 160: 403412.

[50] Shangguan, Z. P., Shao, M. A., Dyckmans, J. (2000): Effects of Nutrition and water deficit on the Net photosynthetic rate and chlorophyll fluorescence in winter wheat. Journal of Plant Physiology 156: 46-51.

[51] Sikuku, P. A., Netondo, G. W., Onyango, J. C., Mysyimi, D. M. (2010): Chlorophyll fluorescence, protein, and chlorophyll content of three rainfed rice varieties under varying irrigation regimes. - Journal of Agricultural and Biological Science 5: 19-25.

[52] Singh, S. J., Singh, S. K. (2013): Genetic variability analysis in coriander (Coriandrum sativum L.). - Journal of Spices and Aromatic Crops 22: 81-84.

[53] Su, Z., Ma, X., Guo, H., Sukiran, N. L., Guo, B., Assmann, S. M., Ma, H. (2013): Flower development under drought stress: Morphological and transcriptomics analyses reveal acute responses and long-term acclimation in Arabidopsis. - Plant Cell 25: 3785-3807.

[54] Tatrai, Z. A., Sanoubar, R., Pluhar, Z., Mancarella, S., Orsini, F., Gianquinto, G. (2016): Morphological and physiological plant responses to drought stress in Thymus citriodorus. - International Journal of Agronomy ID 4165750.

[55] Thomas, D. S., Turner, D. W. (2001): Banana (Musa sp.) leaf gas exchange and chlorophyll fluorescence in response to soil drought, shading, and lamina folding. Scientia Horticulturae 90: 93-108.

[56] U. S. Department of Agriculture Forest Science, Natural Resource Conservation Service (2010): The Plants Database. - http://plants.usda.gov.

[57] Van, D. T., Verhoef, C. W., Timmermans, J., Verhoef, A., Su, Z. (2009): An integrated model of soil-canopy spectral radiance observations, photosynthesis, fluorescence, temperature, and energy balance. - Biogeosciences Discussion 6: 6025-6075.

[58] Van, K. O., Snel, J. F. H. (1990): The use of chlorophyll nomenclature in plant stress physiology. - Photosynthesis Research 25: 147-150.

[59] Wang, P., Kaiser, Y. I., Menegat, A., Gerhards, R. (2015): Weed PAM: A rapid in-season herbicide resistance detector. $-17^{\text {th }}$ European Weed Research Society Symposium 137: 287-291.

[60] Wang, W. L., Wan, Y. J., Liu, B., Wang, G. X., Tang, X. Y., Chen, X., Liang, B., Zhuang, W. (2013): Influence of soil gradual drought stress on Acorus calamus growth and photosynthetic fluorescence characteristics. - Acta Ecologica Sinica 33: 3933-3940.

[61] Wei, H. T., Li, J., He, X. R. (2007): Genetic diversity of Aegilops tauschii revealed by SSR markers. - Southwest China Journal of Agricultural Sciences 20: 270-274.

[62] Wei, H. T., Li, J., Peng, Z. S., Lu, B., Zhao, R., Yang, Z. J. (2008): Relationships of Aegilops tauschii revealed by DNA fingerprints: The evidence for agriculture exchange between China and the West. - Progress in Natural Science 18: 1525-1531.

[63] Wu, G. L., Duan, R. Y., Wang, Z. G., Zhang, Z. X., Wu, L. F. (2010): Effects of drought stress and rehydration on chlorophyll fluorescence characteristics in Fragaria $\times$ ananassa Duch. - Acta Ecologica Sinica 30: 3941-3946.

[64] Yamaguchi-Shinozaki, K., Shinozaki, K. (2006): Transcriptional regulatory networks in cellular responses and tolerance to dehydration and cold stresses. - Annual Review of Plant Biology 57: 781-803.

[65] Yang, W. Q., Gu, M. Y., Kou, J. C. (2013): Effect of drought and rewatering on the photosynthesis and chlorophyll fluorescence of Coronilla varia. - Acta Agrestia Sinica 21: 1130-1135.

[66] Ying, J., Lee, E. A., Tollenaar, M. (2002): Response of Leaf Photosynthesis during the grain-gilling period of maize to the duration of cold exposure, acclimation, and incident PPFD. - Crop Science 42: 1164-1172.

[67] Zhang, C. X., Li, X. J., Huang, H. J., Wei, S. H. (2007): Alert and prevention of the spreading of Aegilops tauschii, the worst weed in a wheat field. - Acta Phytophylacica Sinica 34: 103-106 (in Chinese). 